\title{
Rare earth doped lead-free germanate glasses for modern photonics
}

\author{
Joanna Janek, ${ }^{1}$ Joanna Pisarska, ${ }^{1}$ and Wojciech A. Pisarski, ${ }^{* 1}$ \\ ${ }^{1}$ Institute of Chemistry, University of Silesia, Szkolna 9, 40-007 Katowice
}

Received May 09, 2014; accepted June 22, 2014; published June 30, 2014

\begin{abstract}
Lead-free germanate glasses doped with rare earth ions were synthesized and next studied using excitation and luminescence spectroscopy. Rare earths were limited to $\mathrm{Pr}^{3+}, \mathrm{Eu}^{3+}$ and $\mathrm{Er}^{3+}$ ions. Several luminescence bands correspond to transitions originating from the ${ }^{3} \mathrm{P}_{0}$ and ${ }^{1} \mathrm{D}_{2}$ states of $\mathrm{Pr}^{3+}$, the ${ }^{5} \mathrm{D}_{0}$ state of $\mathrm{Eu}^{3+}$, the ${ }^{4} \mathrm{~S}_{3 / 2},{ }^{4} \mathrm{~F}_{9 / 2}$ and ${ }^{4} \mathrm{I}_{13 / 2}$ states of $\mathrm{Er}^{3+}$, respectively. The relatively long lifetime for the upper ${ }^{4} \mathbf{I}_{13 / 2}$ laser state of $\mathrm{Er}^{3+}$ suggest that lead-free germanate glasses are promising materials for near-infrared optical amplifiers.
\end{abstract}

Inorganic glasses are well known as promising materials in modern photonics [1]. Due to their unique thermal and spectroscopic properties, they are widely used in the field of solid-state laser [2] and optical fibres [3-5] technologies. Trivalent rare earths, as optically active ions, are incorporated into glass host matrices for upconversion luminescence [6] and fibre amplifiers [7]. Among several inorganic glass systems, glasses containing cadmium or lead are classified as toxic raw materials and consequently, often eliminated from various practical applications due to their hazardous effect on health and environment. Therefore, lead- and cadmium-free bismuthate glasses are alternatively proposed for potential applications in photonics [8]. The intension of our work was to fabricate rare earth doped lead-free germanate glasses and to examine their optical properties. The previous results indicate that germanate glass in the $\mathrm{BaO}$ $\mathrm{Ga}_{2} \mathrm{O}_{3}-\mathrm{GeO}_{2}$ system is known as a window for a high energy laser HEL system [9] and its properties can be modified by adding/substituting various glass components [10]. A new type host of germanate bulk glass and glass fiber $\left(\mathrm{GeO}_{2}-\mathrm{BaO}-\mathrm{BaF}_{2}-\mathrm{Ga}_{2} \mathrm{O}_{3}-\mathrm{La}_{2} \mathrm{O}_{3}\right)$ singly doped with $\mathrm{Tm}^{3+}$ ions has been investigated for application as an NIR laser material at $1800 \mathrm{~nm}[11,12]$.

Lead-free germanate glasses with the following chemical composition: $60 \mathrm{GeO}_{2}-30 \mathrm{BaO}-9.5 \mathrm{Ga}_{2} \mathrm{O}_{3}-0.5 \mathrm{Ln}_{2} \mathrm{O}_{3}$ (given in $\mathrm{mol} \%$ ), where $\mathrm{Ln}=\mathrm{Pr}$, Eu or $\mathrm{Er}$, were prepared by mixing and melting appropriate amounts of metal oxides of high purity (99.99\%, Aldrich Chemical Co.). A homogeneous mixture was heated in a protective atmosphere of dried argon. Mixed reagents were melted for $0.45 \mathrm{~h}$ at $1200^{\circ} \mathrm{C}$. Excitation and luminescence measurements were performed on a PTI QuantaMaster QM40 coupled with a tunable pulsed optical parametric

$$
{ }^{*} \text { E-mail: wojciech.pisarski@us.edu.pl }
$$

oscillator (OPO), pumped by a third harmonic of a Nd:YAG laser (Opotek Opolette 355 LD). The emission was dispersed by double $200 \mathrm{~mm}$ monochromators. The emission spectra were recorded using a multimode UVVIS PMT (R928) and Hamamatsu H10330B-75 detectors. Spectral measurements were carried out with a resolution of $0.1 \mathrm{~nm}$. Luminescence lifetimes were determined with accuracy of $1 \mu \mathrm{s}$. All measurements were carried out at room temperature.

Figure 1 presents excitation and luminescence spectra of $\mathrm{Pr}^{3+}$ ions in lead-free germanate glasses. Excitation spectrum was monitored at $\lambda_{\mathrm{em}}=645 \mathrm{~nm}$ emission wavelength. The observed bands correspond to transitions originating from the ${ }^{3} \mathrm{H}_{4}$ ground state to the higher-lying ${ }^{3} \mathrm{P}_{2},{ }^{1} \mathrm{I}_{6},{ }^{3} \mathrm{P}_{1}$ and ${ }^{3} \mathrm{P}_{0}$ states of trivalent praseodymium. In order to obtain emission spectrum, the glass sample was excited at $\lambda_{\text {exc }}=450 \mathrm{~nm}\left({ }^{3} \mathrm{P}_{2}\right.$ state of $\left.\operatorname{Pr}^{3+}\right)$.

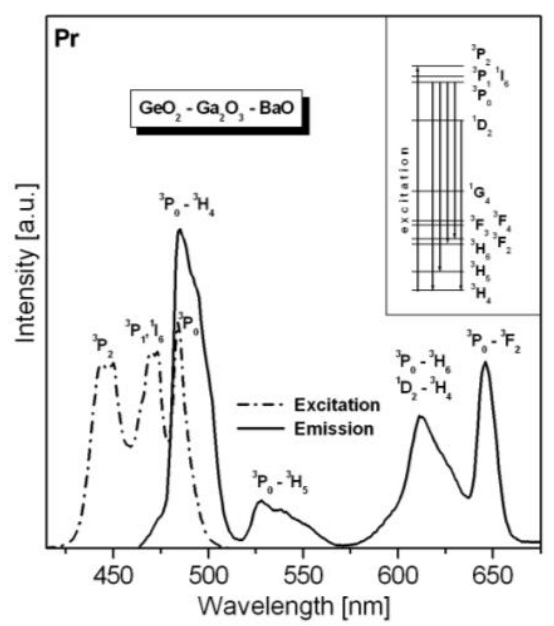

Fig. 1. Excitation and emission of $\operatorname{Pr}^{3+}$ in lead-free germanate glass.

Several emission bands were detected, which are due to ${ }^{3} \mathrm{P}_{0} \rightarrow{ }^{3} \mathrm{H}_{4}, \quad{ }^{3} \mathrm{P}_{0} \rightarrow{ }^{3} \mathrm{H}_{5}, \quad{ }^{1} \mathrm{D}_{2} \rightarrow{ }^{3} \mathrm{H}_{4}, \quad{ }^{3} \mathrm{P}_{0} \rightarrow{ }^{3} \mathrm{H}_{6}, \quad{ }^{3} \mathrm{P}_{0} \rightarrow{ }^{3} \mathrm{~F}_{2}$ transitions of $\mathrm{Pr}^{3+}$, respectively. All electronic transitions are schematized on the energy level scheme of $\operatorname{Pr}^{3+}$ ions (Inset of Fig. 1). The ${ }^{3} \mathrm{P}_{0} \rightarrow{ }^{3} \mathrm{H}_{4}$ (blue) and ${ }^{3} \mathrm{P}_{0} \rightarrow{ }^{3} \mathrm{~F}_{2}$ (red) transitions located at about $490 \mathrm{~nm}$ and $645 \mathrm{~nm}$ are the most intense emission lines. The later ${ }^{3} \mathrm{P}_{0} \rightarrow{ }^{3} \mathrm{~F}_{2}$ transition corresponds to "hypersensitive transition" of $\mathrm{Pr}^{3+}$, which is related to the polarizability and glass host structure [13]. 
Luminescence decays from excited states of $\operatorname{Pr}^{3+}$ ions were also measured under $450 \mathrm{~nm}$ excitation $\left({ }^{3} \mathrm{P}_{2}\right.$ state $)$ while monitoring various emission wavelengths. Measured lifetimes are close to about $10 \mu \mathrm{s}$, when decay curves were monitored at 620 or $645 \mathrm{~nm}$ emission wavelengths, respectively. They correspond to ${ }^{3} \mathrm{P}_{0}$ state of $\operatorname{Pr}^{3+}$. Decay curve measurement under $450 \mathrm{~nm}$ excitation and 590nm emission wavelength gives quite different experimental results. In this case, the luminescence lifetime is close to $25 \mu \mathrm{s}$ and its value is similar to that obtained from decay curve measurement under direct excitation of ${ }^{1} \mathrm{D}_{2}$ state by $590 \mathrm{~nm}$ line and monitoring $620 \mathrm{~nm}$ emission wavelength. It also confirmed that the broad band located in the reddish-orange spectral range overlaps two luminescence lines, which correspond to transitions originating from ${ }^{1} \mathrm{D}_{2}$ (orange band) and ${ }^{3} \mathrm{P}_{0}$ (red band) excited states of $\operatorname{Pr}^{3+}$.

Figure 2 shows excitation and luminescence spectra of $\mathrm{Eu}^{3+}$ ions in lead-free germanate glasses. The excitation spectra were monitored at the $610 \mathrm{~nm}$ emission wavelength. Several observed bands correspond to transitions originating from the ${ }^{7} \mathrm{~F}_{0}$ ground state to the higher-lying ${ }^{5} \mathrm{G}_{2},{ }^{5} \mathrm{~L}_{6},{ }^{5} \mathrm{D}_{3},{ }^{5} \mathrm{D}_{2}$ and ${ }^{5} \mathrm{D}_{1}$ states of trivalent europium.

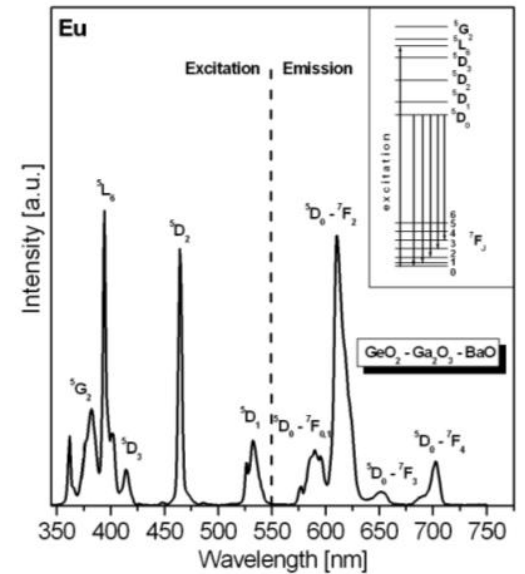

Fig. 2. Excitation and emission of $\mathrm{Eu}^{3+}$ in lead-free germanate glass.

The emission spectrum was measured under excitation by $393 \mathrm{~nm}$ line $\left({ }^{5} \mathrm{~L}_{6}\right.$ state). The excitation energy transfers nonradiatively very fast to the ${ }^{5} \mathrm{D}_{0}$ state due to small energy gaps between higher-lying excited states of $\mathrm{Eu}^{3+}$. The energy gap between ${ }^{5} \mathrm{D}_{0}$ state and lower-lying ${ }^{7} \mathrm{~F}_{6}$ state is quite large (Inset of Fig. 2). It suggests that radiative transitions from ${ }^{5} \mathrm{D}_{0}$ state are the dominant excited state relaxation. Several luminescence bands are observed, which correspond to ${ }^{5} \mathrm{D}_{0} \rightarrow{ }^{7} \mathrm{~F}_{\mathrm{J}} \quad(\mathrm{J}=0 \div 4)$ transitions of $\mathrm{Eu}^{3+}$ ions. Two of them, ${ }^{5} \mathrm{D}_{0} \rightarrow{ }^{7} \mathrm{~F}_{2}$ (red) and ${ }^{5} \mathrm{D}_{0} \rightarrow{ }^{7} \mathrm{~F}_{1}$ (orange) transitions of $\mathrm{Eu}^{3+}$ are important from the spectroscopic point of view. The ${ }^{5} \mathrm{D}_{0} \rightarrow{ }^{7} \mathrm{~F}_{2}$ red transition is an electric-dipole transition, which strongly depends on the environment surrounding $\mathrm{Eu}^{3+}$ ions. This transition is also called hardly sensitive transition. The ${ }^{5} \mathrm{D}_{0} \rightarrow{ }^{7} \mathrm{~F}_{1}$ orange transition has a magnetic-dipole character, which is less sensitive and independent of ligands around $\mathrm{Eu}^{3+}$. The integrated luminescence intensity of ${ }^{5} \mathrm{D}_{0} \rightarrow{ }^{7} \mathrm{~F}_{2}$ transition to the integrated luminescence intensity of ${ }^{5} \mathrm{D}_{0} \rightarrow{ }^{7} \mathrm{~F}_{1}$ transition is defined as red-to-orange luminescence intensity ratio $\mathrm{R} / \mathrm{O}$ of $\mathrm{Eu}^{3+}$. Based on the integrated luminescence intensities of each transition, the factor of $\mathrm{R} / \mathrm{O}\left(\mathrm{Eu}^{3+}\right)$ was calculated for lead-free germanate glass. The $\mathrm{R} / \mathrm{O}$ factor of $\mathrm{Eu}^{3+}$ informs us about local asymmetry and covalence bonding between rare earths and nearest surroundings. Their values increase with increasing asymmetry and covalency. In our case, the factor of $\mathrm{R} / \mathrm{O}\left(\mathrm{Eu}^{3+}\right)$ is above 4 , which suggests that the nearest surrounding $\mathrm{Eu}^{3+}$ ions is covalent in character. Luminescence decay from the ${ }^{5} \mathrm{D}_{0}$ state of $\mathrm{Eu}^{3+}$ ions was also measured. The luminescence decay curve is nearly exponential and the measured lifetime is close to $1.25 \mathrm{~ms}$.

Finally, the luminescence properties of Er-doped leadfree germanate glass in the visible and near-infrared spectral ranges have been studied. Figure 3 presents excitation and luminescence spectra of $\mathrm{Er}^{3+}$ in lead-free germanate glass. The spectra were measured in the UVvisible region. The excitation spectrum was monitored at the $545 \mathrm{~nm}$ emission wavelength. The observed bands in the $350-500 \mathrm{~nm}$ correspond to transitions originating from the ${ }^{4} \mathrm{I}_{15 / 2}$ ground state to the higher-lying ${ }^{4} \mathrm{G}_{9 / 2},{ }^{4} \mathrm{G}_{11 / 2}$, ${ }^{2} \mathrm{G}_{9 / 2},{ }^{2} \mathrm{~F}_{3 / 2},{ }^{4} \mathrm{~F}_{5 / 2}$ and ${ }^{4} \mathrm{~F}_{7 / 2}$ states of trivalent erbium. The emission spectrum was measured under excitation by the $488 \mathrm{~nm}$ line $\left({ }^{4} \mathrm{~F}_{7 / 2}\right.$ state $)$. Generally, two emission lines in the green and red spectral region were successfully observed. The most intense green line corresponds to ${ }^{2} \mathrm{H}_{11 / 2},{ }^{4} \mathrm{~S}_{3 / 2} \rightarrow{ }^{4} \mathrm{I}_{15 / 2}$ transition, whereas the less intense red line is due to ${ }^{4} \mathrm{~F}_{9 / 2} \rightarrow{ }^{4} \mathrm{I}_{15 / 2}$ transition of erbium, respectively. All transitions are indicated on the energy level scheme (Inset of Fig. 3).

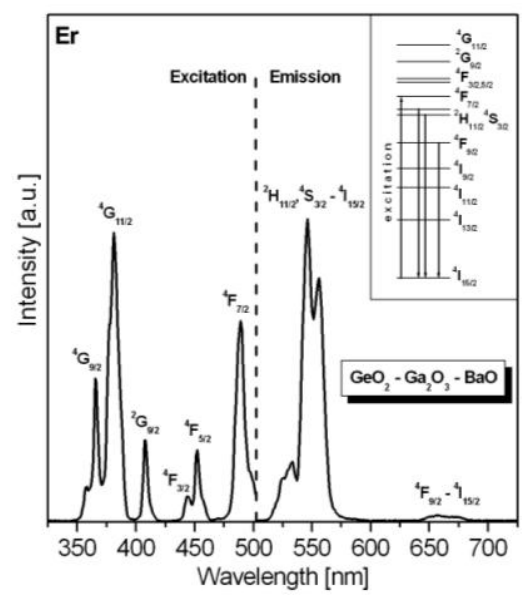

Fig. 3. Excitation and emission of $\mathrm{Er}^{3+}$ in lead-free germanate glass.

(C) 2014 Photonics Society of Poland 
The near-infrared luminescence spectrum of $\mathrm{Er}^{3+}$ ions in lead-free germanate glass is presented in Fig. 4. The glass sample was excited by the $488 \mathrm{~nm}$ line. The observed NIR luminescence at about $1530 \mathrm{~nm}$ corresponds to the main ${ }^{4} \mathrm{I}_{13 / 2} \rightarrow{ }^{4} \mathrm{I}_{15 / 2}$ laser transition of $\mathrm{Er}^{3+}$, which is demanded for broadband optical amplifiers operating in the third telecommunication window.

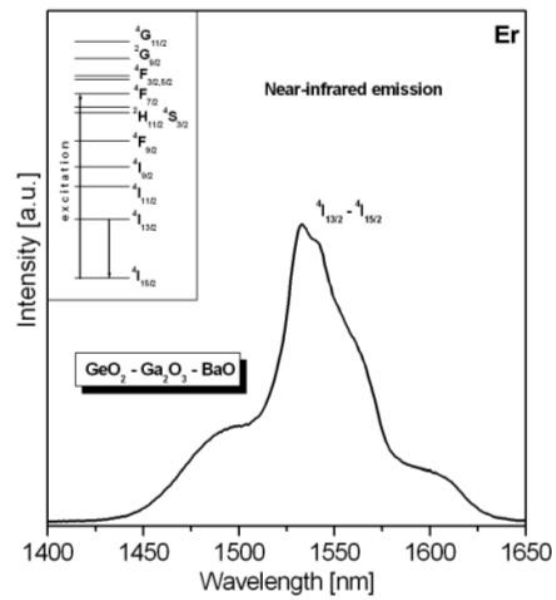

Fig. 4. Near-infrared emission of $\mathrm{Er}^{3+}$ in lead-free germanate glass.

One of the most important spectroscopic parameters is the measured luminescence lifetime for the excited level of rare earth ions. The relatively long luminescence lifetime of the metastable level required for the high population inversion is a critical factor in the success of Er-doped fiber amplifiers (EDFA) in the optical communications. The luminescence decay curve for the ${ }^{4} \mathrm{I}_{13 / 2}$ state of $\mathrm{Er}^{3+}$ was well fitted to a single exponential function because of the low activator concentration and the lack of energy transfer processes between erbium ions. The measured lifetime for ${ }^{4} \mathrm{I}_{13 / 2}$ state of $\mathrm{Er}^{3+}$ ions in leadfree germanate glass is close to $5.35 \mathrm{~ms}$ and its value is higher in comparison to similar germanate glasses containing lead [14-16].

In conclusion, lead-free germanate glass systems in $60 \mathrm{GeO}_{2}-30 \mathrm{BaO}-9.5 \mathrm{Ga}_{2} \mathrm{O}_{3}-0.5 \mathrm{Ln}_{2} \mathrm{O}_{3}$ molar composition were prepared and next studied using excitation and luminescence spectroscopy. The rare earths as optically active ions were limited to $\mathrm{Pr}^{3+}, \mathrm{Eu}^{3+}$ and $\mathrm{Er}^{3+}$ ions. Here, the experimental results are presented and discussed in relation to practical applications in modern visible and near-infrared photonics.

Several luminescence bands are successfully observed, corresponding to characteristic electronic transitions of trivalent rare earth ions. For $\mathrm{Pr}^{3+}$-doped glass sample, the ${ }^{3} \mathrm{P}_{0} \rightarrow{ }^{3} \mathrm{H}_{4}$ (blue) and ${ }^{3} \mathrm{P}_{0} \rightarrow{ }^{3} \mathrm{~F}_{2}$ (red) transitions located at about $490 \mathrm{~nm}$ and $645 \mathrm{~nm}$ are the most intense emission lines. The observed luminescence bands of $\mathrm{Eu}^{3+}$ are due to ${ }^{5} \mathrm{D}_{0} \rightarrow{ }^{7} \mathrm{~F}_{\mathrm{J}}(\mathrm{J}=0 \div 4)$ transitions. Two of them, ${ }^{5} \mathrm{D}_{0} \rightarrow{ }^{7} \mathrm{~F}_{2}$ (red) and ${ }^{5} \mathrm{D}_{0} \rightarrow{ }^{7} \mathrm{~F}_{1}$ (orange) transitions of $\mathrm{Eu}^{3+}$ ions are important from the spectroscopic point of view. The integrated emission intensities of both transitions defined as red-to-orange luminescence intensity ratio $\mathrm{R} / \mathrm{O}\left(\mathrm{Eu}^{3+}\right)$ inform us about local asymmetry and covalence bonding between rare earths and the nearest surroundings. Quite a high value of the $\mathrm{R} / \mathrm{O}$ factor suggests that the nearest surrounding $\mathrm{Eu}^{3+}$ ions are covalent in character. Luminescence spectra for an $\mathrm{Er}^{3+}$-doped glass sample were registered in the visible and near-infrared spectral ranges. The visible luminescence spectrum consists of two green and red bands, which are due to the ${ }^{2} \mathrm{H}_{11 / 2}$, ${ }^{4} \mathrm{~S}_{3 / 2} \rightarrow{ }^{4} \mathrm{I}_{15 / 2}$ and ${ }^{4} \mathrm{~F}_{9 / 2} \rightarrow{ }^{4} \mathrm{I}_{15 / 2}$ transitions of erbium, respectively. The observed NIR luminescence at about $1530 \mathrm{~nm}$ corresponds to the main ${ }^{4} \mathrm{I}_{13 / 2} \rightarrow{ }^{4} \mathrm{I}_{15 / 2}$ laser transition of $\mathrm{Er}^{3+}$. The relatively long luminescence lifetime for the upper ${ }^{4} \mathrm{I}_{13 / 2}$ laser state of $\mathrm{Er}^{3+}$ suggest that lead-free germanate glasses are promising materials for near-infrared broadband optical amplifiers operating in the third telecommunication window.

Acknowledgements: The National Science Centre (Poland) supported this work under research project 2011/03/B/ST7/01743

\section{References}

[1] M. Yamane, Y. Asahara, Glasses for photonics (Cambridge University Press 2000).

[2] A. Jha et al., Prog. Mater. Sci. 57, 1426 (2012).

[3] J.S. Wang, E.M. Vogel, E. Snitzer, Opt. Mater. 3, 187 (1994).

[4] J. Dorosz, Ceramics 86 (2005).

[5] J. Dorosz, R.S. Romaniuk, INTL J. Electron. Telecom. 57, 191 (2011).

[6] M. Kochanowicz, W. Mazerski, J. Żmojda, K. Czajkowski, D. Dorosz, Phot. Lett. Poland 5, 35 (2013)

[7] J. Żmojda, D. Dorosz, M. Kochanowicz, J. Dorosz, Phot. Lett. Poland 2, 76 (2010)

[8] H. Lin, E.Y.B. Pun, B.J. Chen, Y.Y. Zhang, J. Appl. Phys. 103, 056103 (2008)

[9] S.S. Bayya, G.D. Chin, J.S. Sanghera, I.D. Aggarwal, Opt. Expr. 14, 11687 (2006).

[10] J.M. Jewell, P.L. Higby, I.D. Aggarwal, J. Am. Ceram. Soc. 77, 697 (1994)

[11] R.R. Xu, Y. Tian, M. Wang, L.L. Hu, J.J. Zhang, Appl. Phys. B 102 , 109 (2011).

[12] R. Xu, Y. Tian, L. Hu, J. Zhang, Appl. Phys. B 104, 839 (2011)

[13] V.K. Tikhomirov, S.A. Tikhomirova, J. Non-Cryst. Solids 274, 50 (2000).

[14] R. Balda, A. Oleaga, J. Fernandez, J.M. Fdez-Navarro, Opt. Mater. 24, 83 (2003)

[15] H. Yamauchi, Y. Ohishi, Opt. Mater. 27, 679 (2005).

[16] W.A. Pisarski, Ł. Grobelny, J. Pisarska, R. Lisiecki, W. RybaRomanowski, J. Alloys Compd. 509, 8088 (2011). 